\title{
2010 年青海玉树地震震源过程
}

\author{
张勇 ${ }^{*}$, 许力生 ${ }^{\dagger}$, 陈运泰 ${ }^{\dagger}$ \\ 中国地震局地球物理研究所, 北京 100081 \\ *E-mail: zhangyong@ @ cea-igp.ac.cn; 联系人, †E-mail: xuls@cea-igp.ac.cn, †† E-mail: chenyt@cea-igp.ac.cn \\ 收稿日期: 2010-05-04; 接受日期: 2010-06-24 \\ 国家自然科学基金项目(批准号: 40904013, 40874026)和中国地震局地球物理研究所基本科研专项(编号: DQJB09B06)资助
}

2010 年 4 月 14 日 7 时 49 分(北京时间), 在我国 青海省玉树藏族自治州发生了 $M_{\mathrm{S}} 7.1$ 地震(简称玉树 地震). 根据中国地震台网中心最新测定结果, 玉树 地震震中位置为 $33.2^{\circ} \mathrm{N}, 96.6^{\circ} \mathrm{E}$, 震源深度约 $14 \mathrm{~km}$, 位于玉树城区西北约 $44 \mathrm{~km}$ 处. 截至 2010 年 5 月 30 日, 玉树地震已造成三千多人死亡或失踪、一万多人 受伤、大量房屋倒塌.

玉树地震发生于巴颜喀拉地块(松潘-甘孜地块) 南缘的甘孜-玉树断裂带. 在这条沿北西-南东方向延 伸、以左旋走滑为主的断裂带上, 历史上地震频发 ${ }^{[1,2]}$, 地震活动性较强 ${ }^{[3,4]}$. 玉树地震是该断裂带北西段最近 一百年来发生的最大的一次地震事件. 作为震后应急 响应的重要工作内容之一, 作者在震后约 2.5 小时 得出并发布了这次地震破裂过程的初步结果; 随着 波形数据的逐渐增加, 在震后约 5 小时和 2 天后先 后两次对上述结果进行了修订 (http://www.csi.ac.cn).

为深入理解和认识玉树地震的震源过程, 在应急 响应工作结束后, 作者利用余震记录, 采用经验格林函 数方法, 从勒夫波(Love wave) 中提取了主震的视震源 时间函数, 并据此估计了破裂速度; 在此基础上, 重新 对 $\mathrm{P}$ 波波形进行反演, 得到了比震后应急响应工作更 为准确的玉树地震破裂过程结果. 以上工作概述如下.

\section{1 勒夫波视震源时间函数分析}

玉树地震发生后大约 1.5 小时, 在主震震中附近发 生了一次 $M_{\mathrm{S}} 6.3$ 余震, 其震中位置为 $33.23^{\circ} \mathrm{N}, 96.58^{\circ} \mathrm{E}$, 震源深度约 $10 \mathrm{~km}$ (据青海地震局测定结果). 这次余 震具有与主震相近的震源位置和几乎完全相同的震源 机制 ${ }^{[6]}$ (图 1), 因此可以用它的波形记录作为经验格林
函数来提取主震的视震源时间函数, 分析主震的破裂 特征. 鉴于在很多台站的记录中该余震的 $\mathrm{P}$ 波和 $\mathrm{S}$ 波 的信噪比较低, 作者选用了勒夫波的波形记录.

基于图 2(a)所示的 24 个台站的勒夫波波形记录, 采用 PLD 方法 ${ }^{[7,8]}$ 提取了如图 2(b)所示的勒夫波视震 源时间函数. 由图 2(b) 可见, 方位角相近的台站的勒 夫波视震源时间函数的形状非常相似, 具有一定的共 同性; 随着方位角的变化, 持续时间和两个峰值的位 置均呈规律性的变化, 表现出明显的方向性. 方位角 位于 $100^{\circ} \sim 150^{\circ}$ 范围内的台站的视震源时间函数的持 续时间最短, 约为 $10 \mathrm{~s}$; 而方位角位于 $300^{\circ}$ 左右的台 站的视震源时间函数持续时间最长, 接近 $30 \mathrm{~s}$. 视震

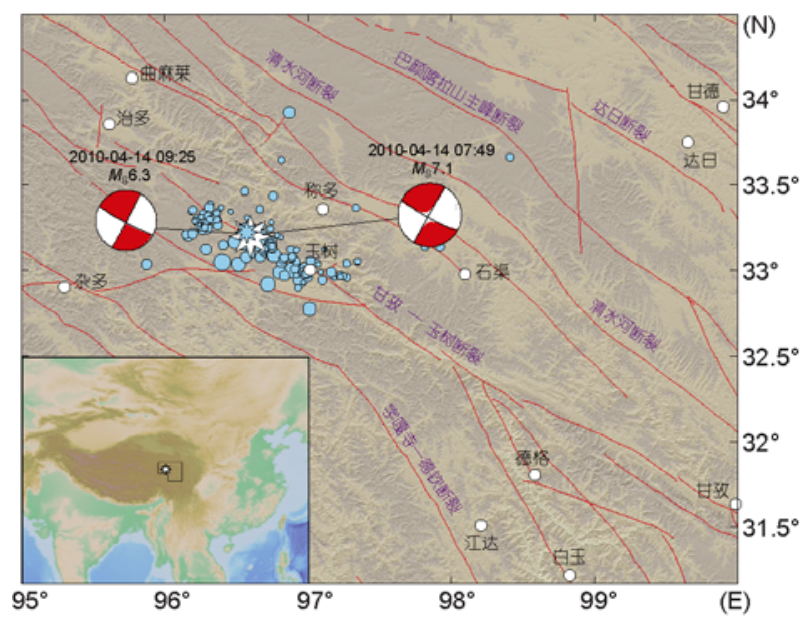

图 1 玉树地震位置及其构造背景

白色大八角星和青色小八角星分别表示玉树地震及 $M_{\mathrm{S}} 6.3$ 余震的震 中位置, 红色实线为断层 ${ }^{[5]}$, 两个 “海滩球”分别表示玉树地震主震 及其最大余震震源机制解的下半球投影 ${ }^{[6]}$, 青色圆圈为玉树地震 5 天后发生的余震震中位置(据青海省地震局张晓青研究员)

引用格式: Zhang Y, Xu L S, Chen Y T. Source process of the 2010 Yushu, Qinghai, earthquake. Sci China Earth Sci, 2010, doi: 10.1007/s11430-010-4045-5 
源时间函数持续时间随方位的变化显示出强烈的“地震 多普勒效应”, 表明这次地震总体上是由震中朝东南方 向 $\left(100^{\circ} \sim 150^{\circ}\right)$ 扩展的单侧破裂事件.

由方位角 $230^{\circ} \sim 330^{\circ}$ 范围的台站的视震源时间函 数(图 2(b)) 可以清楚地分辨出两次子事件; 但在其他 方位角范围的台站上, 两次子事件相距很近而聚合 在一起. 为确定两次子事件的峰值所对应的时空参 数, 根据方位角位于 $230^{\circ} \sim 330^{\circ}$ 范围的台站的视震源 时间函数(图 2(b)) 所显示的两次子事件峰值所对应的 时间，建立如下目标函数:

$$
\Delta(R, T)=\sum_{i}\left|T-\frac{R \cos \left(\phi_{i}-\phi_{s}\right)}{V}-t_{i}\right|=\min ,
$$

式中, $i$ 表示台站序数, $R$ 和 $T$ 分别为与子事件峰值相 对应的空间和时间位置, $V$ 为震中区的勒夫波群速度, $\phi_{i}$ 为第 $i$ 个台站相对于震中的方位角, $\phi_{s}$ 为断层走向, $t_{i}$ 为第 $i$ 个台站的视震源时间函数中子事件峰值出现 的时间. 根据刘超等 $\left[{ }^{[6}\right.$ 确定的玉树地震的震源机制解, 取 $\phi_{s}=119^{\circ}$; 根据彭艳菊等 ${ }^{[9]}$ 关于勒夫波层析成像的 研究结果, 取 $V=3.4 \mathrm{~km} / \mathrm{s}$. 利用遗传算法求解式(1), 得出: 与第一次子事件峰值对应的空间位置位于震 中东南 $3.3 \mathrm{~km}$, 出现在破裂开始后 $2.1 \mathrm{~s}$, 因此, 在 $0 \sim 2.1 \mathrm{~s}$ 内的平均破裂速度约为 $1.6 \mathrm{~km} / \mathrm{s}$; 与第二次子 事件峰值对应的空间位置位于震中东南 $32.9 \mathrm{~km}$, 出 现在破裂开始后 $8.3 \mathrm{~s}$, 因此, 在 $0 \sim 8.3 \mathrm{~s}$ 内的平均破 裂速度约为 $4.0 \mathrm{~km} / \mathrm{s}$. 可见, 玉树地震破裂的扩展是 一个由缓到急的过程, 其中破裂开始后 0 8.3 $\mathrm{s}$ 内的 平均破裂速度甚至超过了当地的 $\mathrm{S}$ 波速度 ${ }^{[10]}$.

\section{P波资料分析}

根据刘超等 ${ }^{[6]}$ 确定的玉树地震的断层面参数, 作 者选用走向 $119^{\circ}$ 倾角 $83^{\circ}$ 的节面作为玉树地震发震
断层所在的平面, 在这个长 $96 \mathrm{~km}$ 、宽 $30 \mathrm{~km}$ 的平面 上，沿走向方向和倾向方向上划分为 $32 \times 10=320$ 个 3 $\mathrm{km} \times 3 \mathrm{~km}$ 的子断层, 由玉树地震的震源参数可确定 初始破裂点位于走向方向上第 5 块、倾向方向上第 5 块子断层处. 选用如图 3(a)所示的 16 个台站的垂直 向 $\mathrm{P}$ 波资料, 基于滑动角可变的线性反演技术 ${ }^{[11]}$, 利 用全球标准速度模型 ${ }^{[12]}$ 和格林函数的反射率计算方 法 ${ }^{[13]}$, 得到了断层面上的时空破裂过程.

根据 P 波反演结果(图 3), 玉树地震释放的标量 地震矩约为 $2.7 \times 10^{19} \mathrm{Nm}$, 相当于矩震级 $M_{\mathrm{W}} 6.9$, 断层 面上平均滑动量约 $0.6 \mathrm{~m}$, 平均应力降约 $15 \mathrm{MPa}$, 与 板内地震典型的应力降 $(10 \mathrm{MPa})$ 水平大体相当; 整 个破裂过程的持续时间约 $16 \mathrm{~s}$, 主要由两次子事件组 成(图 3(b)). 若以初始破裂发生的时刻为时间原点, 则第一次子事件发生于 $0 \sim 5 \mathrm{~s}$, 对应的破裂分布在震 中西北 $10 \mathrm{~km}$ 至震中东南 $10 \mathrm{~km}$ 处, 最大静态滑动量 约为 $0.8 \mathrm{~m}$. 第二次子事件发生于 5 16 s, 对应的破 裂主要发生在走向方向(震中东南方向)上距震中 17 54 km 处(图 3(c)和(e)中的红-橙-黄色区域), 最大 静态滑动量达 $1.8 \mathrm{~m}$, 破裂明显贯穿到地表.

\section{3 讨论与结论}

本文通过勒夫波和 $\mathrm{P}$ 波综合分析得出 2010 年 4 月 14 日青海玉树 $M_{\mathrm{S}} 7.1\left(M_{\mathrm{W}} 6.9\right)$ 地震的破裂过程主要 由两次子事件组成. 从规模上讲, 第一次子事件小于 第二次子事件; 从时间上讲, 第一次子事件发生于地 震破裂起始后 0 5 s, 第二次子事件发生于地震破裂 起始后 5 16 s; 从空间位置讲, 两次子事件分别发生 在震中附近与玉树城区附近, 二者相距约 $30 \mathrm{~km}$, 且
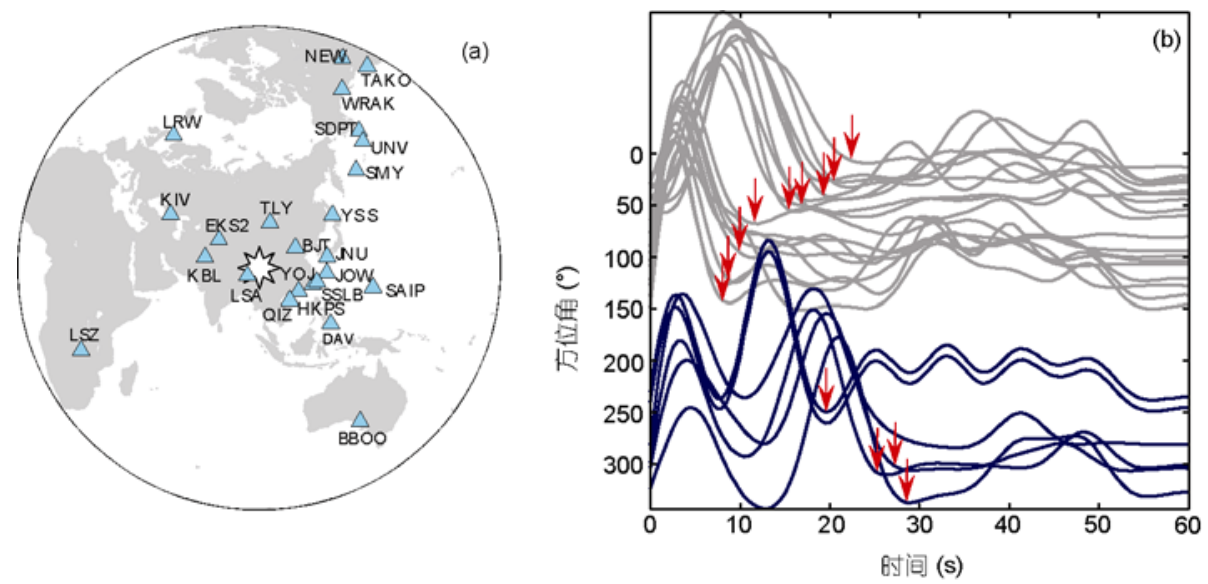

图 2 震中与台站分布(a)和勒 夫波视震源时间函数随台站方 位角的变化(b)

(a)中的白色八角星表示玉树地震 的震中位置, 青色三角形为提取勒 夫波视震源时间函数所选用的台 站; (b)中红色箭头标示了位于不同 方位角的台站处的视震源时间函数 持续时间，蓝色线条表示用于确定 两次子事件峰值所对应的时空参数 的视震源时间函数 

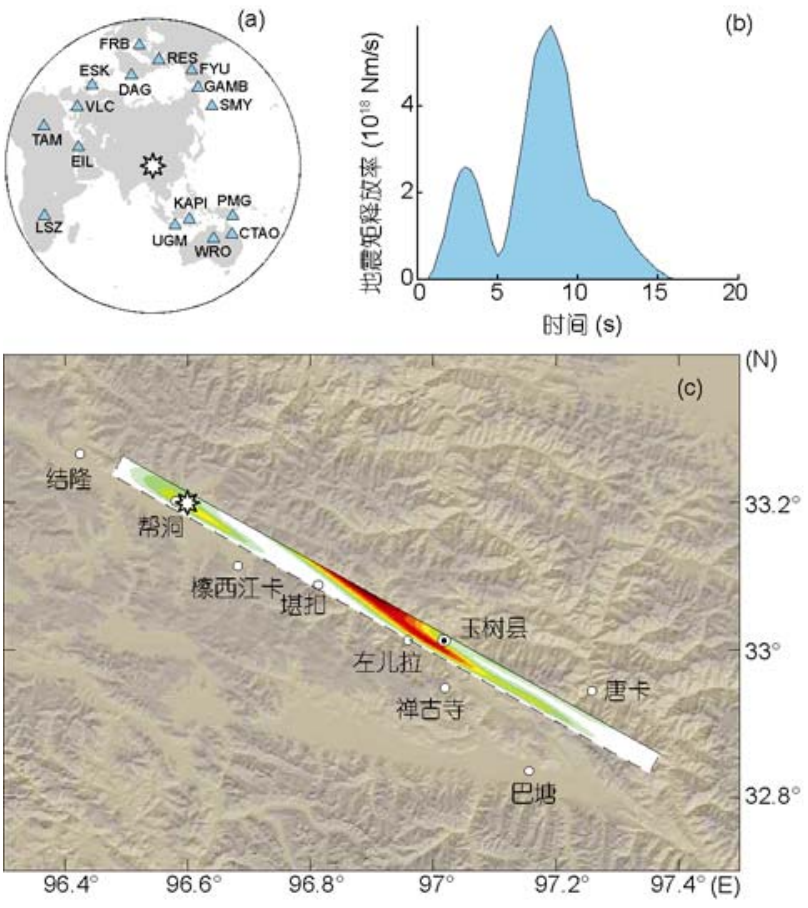

(b)
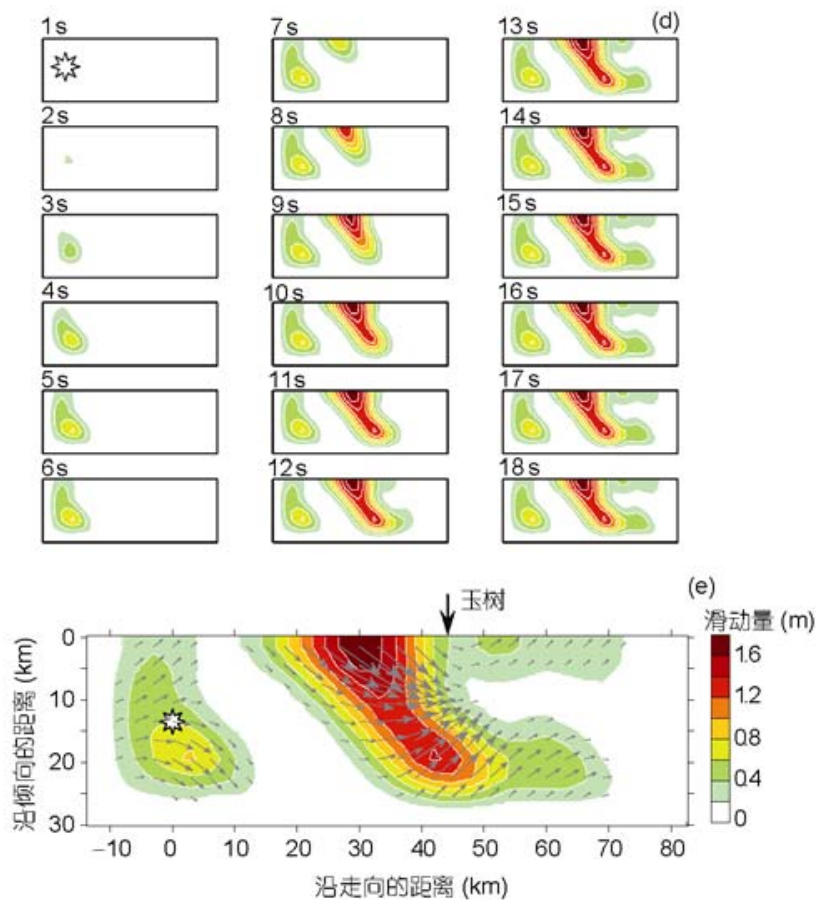

图 3 P 波反演结果

(a) 震中与台站分布; (b) 震源时间函数; (c) 断层面上静态滑动量分布在地表面的投影; (d) 断层面上滑动量的时空分布; (e) 断层面上静态 滑动量分布. (a)和(c)中的白色八角星表示震中位置; (d)和(e)中的八角星表示初始破裂点在断层面上的位置; (e)中的灰色箭头表示滑动矢量

第二次子事件的破裂在玉树城区西北附近贯穿至地 表; 从破裂速度上讲, 与两次子事件峰值对应的平均 破裂速度分别约为 $1.6 \mathrm{~km} / \mathrm{s}$ 和 $4.0 \mathrm{~km} / \mathrm{s}$, 其中 $4.0 \mathrm{~km} / \mathrm{s}$ 的速度超过了震中附近的剪切波速度.

玉树地震属于大地震(震级 $M \geqslant 7$ 的地震)下限边
缘的地震，其震源破裂过程中出现的超剪切破裂现象 表明，超剪切破裂并非仅可能发生于特大地震 ${ }^{[14,15]}$. 以超剪切波速度传播的破裂导致的地震能量聚焦效 应以及规模较大、破裂贯穿到地表的第二次子事件是 玉树城区遭受严重破坏在震源方面的主要原因。

\section{致谢}

IRIS 数据中心提供全球宽频带地震数据，审稿专家提出宝贵意见，在此一并致谢.

\section{参考文献}

1 谢艈寿, 蔡美彪. 中国地震历史资料汇编第三卷(下)。北京：科学出版杜, 1987. 235-236

2 周荣军, 闻学泽, 蔡长星, 等. 甘孜-玉树断裂带的近代地震与未来地震趋势估计. 地震地质, 1997, 19: 115一124

3 李闽锋, 刑成起, 蔡长星, 等. 玉树断裂活动性研究. 地震地质, 1995, 17: 218-224

4 闻学泽, 徐锡伟, 郑荣章, 等. 甘孜-玉树断裂的平均滑动速率与近代大地震破裂. 中国科学 D 辑: 地球科学, 2003, 33: 199-208

5 邓启东, 张培震, 再永康, 等. 中国活动构造基本特征. 中国科学 $\mathrm{D}$ 辑: 地球科学, 2002, 32: 1020-1030

6 刘超, 许力生, 陈运泰. 2010 年 4 月 14 日青海玉树地震快速矩张量解. 地震学报, 2010, 32: 366-368

7 Bertero M, Bindi D, Boccacci P, et al. Application of the projected Landweber method to the estimation of the source time function in seismology. Inv Problems, 1997, 13: 465-486

8 张勇, 许力生, 陈运泰. 提取视震源时间函数的 PLD 方法及其对 2005 年克什米尔 $M_{\mathrm{W}} 7.6$ 地震的应用. 地球物理学报, $2009,52: 572$ $-580$

9 彭艳菊，苏伟，郑月军，等. 中国大陆及海域 Love 波层析成像. 地球物理学报, 2002, 45: 792-803

10 Bassin C, Laske G, Masters G. The current limits of resolution for surface wave tomography in North America. EOS Trans AGU, 2000, 81: F897

11 张勇, 冯万鹏, 许力生, 等. 2008 年汶川大地震的时空破裂过程. 中国科学 D 辑: 地球科学, 2008, 38: 1186-1194

12 Kennett B L N, Engdahl E R. Travel times for global earthquake location and phase identification. Geophys J Int, 1991, 105: 429-465

13 Kennett B L N. Seismic Wave Propagation in Stratified Media. Cambridge: Cambridge University Press, 1983. 1-339

14 杜海林, 许力生, 陈运泰. 利用阿拉斯加台阵资料分析 2008 年汶川大地震的破裂过程. 地球物理学报, 2010, 52: 372-378

15 Das S. The need to study speed. Science, 2007, 317: 905-906 